\title{
Transições na carreira na perspectiva de psicólogos: motivos e estratégias de enfrentamento
}

\author{
Marlize Paulo da Silva \\ Lucy Leal Melo-Silva
}

\begin{abstract}
RESUMO
A construção da carreira ao longo da vida requer habilidades de gerenciamento e adaptação às transições. Assim, este estudo objetivou descrever os motivos e as estratégias utilizadas por uma amostra de 91 psicólogas/os para lidar com as transições. A pesquisa ocorreu por uma plataforma online que continha um questionário sobre as transições na carreira. Com uso do software IraMuteQ foram analisados dois corpus: motivos e estratégias. 0 eixo central sobre os motivos das transições aponta a busca por autonomia e crescimento profissional, qualidade de vida, exploração de novos interesses, insatisfação com a remuneração e fatores externos. No campo das estratégias, ganhou destaque a aquisição de novas experiências, estudos, busca por parcerias, pesquisas sobre o mercado de trabalho, cultivo do networking e a dedicação à pesquisa e à docência. Os motivos e as estratégias apontadas corroboram outros achados da literatura com psicóloga/o e com outros grupos profissionais.
\end{abstract}

Palavras-chave: psicóloga/o; psicologia vocacional; desenvolvimento profissional.

\section{ABSTRACT \\ Career transitions from the perspective of psychologists: reasons and coping strategies}

Career construction along life requires management skills and adaptation to transitions. Thus, this study aimed to describe the motives and strategies used by a sample of 91 psychologists to deal with transitions. The survey was done through an online platform that contained a career transitions questionnaire. Using IraMuteQ software, two corpus were analyzed: motives and strategies. The central axis on the reasons for transitions points to the search for autonomy and professional growth, quality of life, exploration of new interests, dissatisfaction with remuneration and external factors. In the field of strategies, the highlight was the acquisition of new experiences, studies, the search for partnerships, research on the labor market, the cultivation of networking and the dedication to research and teaching. The motives and strategies pointed corroborate other findings in the literature with psychologists and other professional groups.

Keywords: psychologist; vocational psychology; professional development.

O mundo pós-moderno está impondo aos profissionais de diferentes campos de atuação preocupações, objetivas e subjetivas, em torno da necessidade de adaptação às transições na carreira no século XXI. Para além das competências cognitivas e técnicas, estão sendo requeridas competências, habilidades e atributos pessoais, como criatividade, ousadia, curiosidade, autogestão, resiliência, assim como, o desenvolvimento da capacidade para lidar com as incertezas e a de negociar com o mundo do trabalho. Esta dinâmica instável e imprevisível exige mobilizações para se adaptar às mudanças que estão colocadas como desafios à construção da vida e da carreira (Magalhães, 2011; Ribeiro \& Melo-Silva, 2011; Savickas et al., 2009).

\section{Sobre os autores}

M. P. S.

https://orcid.org/0000-00031049-7375

Prefeitura Municipal de Maringá

- Maringá, PR

marlizepaulo@hotmail.com

L. L. M. S.

https://orcid.org/0000-0002-

5890-9896

Universidade de São Paulo -

Ribeirão Preto, SP

lucileal@ffclrp.usp.br

\section{Direitos Autorais}

Este é um artigo de acesso aberto e pode ser reproduzido livremente, distribuído, transmitido ou modificado, por qualquer pessoa desde que usado sem fins comerciais. 0 trabalho é disponibilizado sob a licença Creative Commons CC-BY-NC.

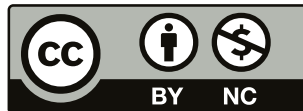




\section{MLE INTERACÃO EM PSICOLOGIA}

Transições ocorrem ao longo da vida, como apontam Schlössberg et al. (1995). Elas podem ser antecipadas (normativas e previsíveis), não antecipadas (eventos não agendados e que se caracterizam como crises ou rupturas) e ou de não eventos (por exemplo, promoção que não ocorre). Especificamente, no que se refere às transições na carreira, ao longo da vida de trabalho, configuram-se diversas situações, entre elas: (a) a transição escola-trabalho -do ensino médio, técnico ou superior para o mundo do trabalho-; (b) as transições trabalho-trabalho -mudanças de emprego, de vínculos (de funções e cargos) e de atividades profissionais-; e (c) a transição trabalho-aposentadoria (Heppner, 1998).

Enquanto algumas transições são derivadas de mudanças no mundo do trabalho outras decorrem de tomada de decisão de carreira. No domínio da Psicologia Vocacional, ou das Carreiras, há diversas linhas que investigam o processo de escoIha, decisão e desenvolvimento da carreira (traço-fator, psicodinâmico, desenvolvimentista-evolutivo, decisional-cognitivo e o transicional; Ribeiro \& Melo-Silva, 2011). O último paradigma mencionado, o transacional, concebe que as Transições na Carreira envolvem um processo em que se deixa de vivenciar um conjunto de atividades, papéis, relacionamentos, crenças e rotinas de trabalho, para estabelecer e criar novos conjuntos nas atividades em casa e na sociedade. Por sua vez, envolve mudanças em relação às premissas no trabalho, sentimentos e comportamentos, implica custos pessoais e financeiros às organizações e instituições, aos próprios indivíduos e às suas famílias (Anderson et al., 2012; Magalhães, 2011).

Diversas são as razões que impulsionam as pessoas à decisão de mudarem o percurso de suas trajetórias profissionais. Quando se trata de uma transição de natureza voluntária, ou seja, que foi realizada por escolha própria, a literatura destaca que ela ocorre por fatores como a necessidade de equilibrar a vida familiar e o trabalho (Cabrera, 2007; Gomes \& Teixeira, 2000; Quishida \& Casado, 2009; Uvaldo, 2010), por necessidade de encontrar um trabalho que lhe traga mais identidade profissional (Joia \& Mangia, 2017; Uvaldo, 2010), para adquirir novos conhecimentos e ampliar habilidades (Chudzikowski et al., 2009; Donohue, 2007; Joia \& Mangia, 2017), poder trabalhar com mais autonomia (Carless \& Arnup, 2011), desvincular-se das pressões negativas dos ambientes corporativos, pela insegurança e instabilidade dos empregos, por conflitos relacionais e insatisfação com o empregador, o trabalho ou com o chefe (Carless \& Arnup, 2011; Rigotti et al., 2014) e ainda pelo choque percebido entre a realidade do mercado de trabalho e expectativas relativas ao exercício da profissão (Peake \& McDowall, 2012). Por outro lado, as transições de caráter involuntário são aquelas propiciadas pelas variáveis externas à escolha do indivíduo, como demissões ou falências, mudanças de cidade ou de país, doenças incapacitantes, transferências e promoções inesperadas ou indese- jadas e até mesmo a conclusão dos estudos e ingresso da atividade profissional (Anderson et al., 2012).

Nesse contexto, estudos indicam que determinantes como os aspectos individuais e recursos internos facilitam a adaptação às transições na carreira, de modo que indivíduos mais abertos às mudanças, que apresentam prontidão, que gostam de correr riscos e são mais resilientes, seguros e confiantes quanto ao gerenciamento da mudança, possuem maior adaptabilidade e maiores chances de sucesso nas transições (Anderson et al., 2012; Carless \& Arunp, 2011; Donohue, 2007; Heppner, 1998; Kilimnik \& Rodrigues, 2000; Murtagh et al., 2011).

Schlössberg et al. (1995) e Anderson et al. (2012) postulam o modelo de gerenciamento das transições na carreira, ou seja, as quatro categorias de fatores cruciais para o entendimento e a intervenção em processo de transição, o sistema 4S (situation, self, support, strategies). A situação compreende os gatilhos disparadores do processo de transição, a natureza, o momento da transição e seus impactos na vida em geral. Os aspectos do self, compreendem as características de personalidade e os temas da vida individual. Os apoios incluem as fontes e os recursos de ajuda disponíveis. As estratégias referem-se ao estilo de enfrentamento utilizado pelo indivíduo para a adaptação às mudanças. Indicam, por exemplo, que o redirecionamento da carreira visa identificar ações cognitivas, emocionais e comportamentais (coping) que propiciem o ajustamento da transição, concretizadas através de um planejamento da carreira.

Por sua vez, Chen (2005) acrescenta uma série de orientações subjetivas e objetivas para a mobilização e enfrentamento das transições, as quais podem ser ainda mais eficazes durante um processo de Aconselhamento de Carreira. Algumas delas são: compreender que transições são eventos naturais no curso da vida, sobretudo no mundo pós-moderno; adotar uma perspectiva transformadora mesmo quando se trata de uma transição involuntária; firmar um compromisso com a carreira, ainda que outras mudanças simultâneas ocorram e façam adiar os objetivos maiores traçados inicialmente; fortalecer a resistência psicológica para lidar com incertezas da transição; buscar e acumular informações que ajudarão nos posicionamentos e nas tomadas de decisões, além de se preparar e qualificar para novos campos de trabalho; desenvolver um planejamento estratégico flexível para as transições inesperadas (e esperadas), permitindo alcançar uma visão do futuro e; reforçar o senso de autoeficácia e a determinação psicológica.

Especificamente, no caso da transição universidade-trabaIho, que é antecipada e esperada, estudos apontam sucesso na transição e maior adaptação ao mundo do trabalho se os universitários relatam maior envolvimento com atividades extracurriculares, interação com professores fora da sala de aula, realização de atividades práticas, estágios e monitorias 


\section{M." INTERACÃO EM PSICOLOGIA}

e cultivo de contatos das redes sociais (Monteiro \& Almeida, 2015; Teixeira et al., 2007; Teixeira \& Gomes, 2004).

Em situações de transições trabalho-trabalho, foco deste estudo, as que ocorrem no transcurso da carreira e envolvem mudanças de emprego, posição ou trabalho, de atividades dentro ou fora da profissão, sejam elas de ordem voluntária ou involuntária, estudos constatam que os indivíduos adotam algumas estratégias específicas para enfrentá-las e se ajustar. Alguns exemplos de estratégias apontadas na literatura são: autoavaliar suas habilidades e limitações (Faulkner, 2007); estar em aprendizagem contínua (Baruch \& Quick, 2009; Faulkner, 2007; Muja \& Appelbaum, 2012; Nooney et al., 2010; Uvaldo, 2010); empreender ações de coping focado no problema e na emoção, particularmente no gerenciamento do estresse e na reestruturação cognitiva da situação (Cohen-Scali, 2015; Kilimnik \& Rodrigues, 2000; Krumboltz et al., 2013; Murtagh et al., 2011; Tan \& Kramer, 2012); avaliar oportunidades e tendências do mercado de trabalho (Cohen-Scali, 2015; Duarte \& Silva, 2013; Muja \& Appelbaum, 2012; Tan \& Kramer, 2012), ampliar e cultivar a rede de contatos (Tan \& Kramer, 2012; Muja \& Appelbaum, 2012; Cohen-Scali, 2015); aproveitar o know-how de experiências de outros empregos e serviços (Quishida \& Casado, 2009; Muja \& Appelbaum, 2012); assim como, atuar como consultor autônomo, estabelecer parcerias e vincular-se às cooperativas de trabalho (Kilimnik \& Rodrigues, 2000; Quishida \& Casado, 2009). Particularmente, no caso das transições em meio da carreira que ocorrem involuntariamente, também foram identificadas outras movimentações como comunicar sua condição àqueles que encorajam e aprovam a mudança e suas escolhas, fortalecendo a base de apoio social (Tan \& Kramer, 2012), trabalhar com flexibilidade entre os empregos, vínculos e serviços prestados (Bendassolli et al., 2015; Veloso \& Dutra, 2011) e buscar auxílio profissional mediante o Aconselhamento de Carreira (Krumboltz et al., 2013).

Como já destacada, a construção da carreira na pós-modernidade se sustenta em imprevisibilidades e incertezas, transformando em rotina a vivência das transições na carreira de trabalhadores e profissionais de todas as áreas e ciências, incluindo a Psicologia, foco deste estudo. No tocante aos psicólogas/os brasileiros, a própria transformação que a ciência psicológica vem enfrentando no país nas últimas décadas, os lança em territórios nos quais as novas formas de fazer e praticar a Psicologia, para além dos modelos tradicionais de atuação -que têm valor e demanda-, possibilitam intervenções também no campo das políticas sociais (Silva \& Alexandre, 2019). Segundo Rechtman e Bock (2019), o processo de reorientação da Psicologia a coloca numa articulação com os movimentos sociais, a defesa de diversas políticas públicas e das minorias e outros debates envoltos aos problemas e dificuldades do cotidiano do povo brasileiro. Além disso, a profissão cresceu desde as últimas décadas, em decorrência do aumento no número de graduados e o crescimento da demanda no setor público-social (Travassos \& Mourão, 2018). Mudanças de paradigmas podem implicar em desafios para a construção da identidade profissional do psicóloga/o, como destacam Mazer e Melo-Silva (2010). 0 aumento dos profissionais e das demandas pelo trabalho do psicóloga/o possibilitam novos horizontes de atuação profissional, assim como, estimulam o interesse por mais estudos acerca da profissão no Brasil e das movimentações dos psicólogas/os no mundo do trabalho.

Algumas das principais investigações em relação à carreira e à atuação do psicóloga/o brasileiro são: o estudo de Bastos e Gomide (1989), os levantamentos do Conselho Federal de Psicologia (CFP, 2004) e de Lhullier (2013) e a coletânea de publicações do livro intitulado $O$ trabalho do Psicólogo no Brasil, organizado por Bastos e Gondim (2010). Outros estudos conduzidos com amostras menores (Bedin, 2010; Carvalho, 2007; Cruz, 2016; Gómez, 2006; Kilimnik \& Rodrigues, 2000; Leite et al., 2011; Marcondes, 2014; Nogueira et al., 2015; Santos et al., 2014) também proporcionam relevantes achados e implicações.

Em sua maioria, os estudos destacam a insatisfação com a remuneração. Heloani et al. (2010) apontaram que metade dos psicólogas/os investigados [n=2774 respostas válidas em estudo de ampla amostra nacional na obra de Bastos e Gondim (2010)] ganha até cinco salários mínimos, sendo que os docentes são os mais bem remunerados. Isso repercute em compensar o baixo salário com mais horas trabalhadas, pois muitos possuem diversos vínculos como assalariados e autônomos. Ademais, verificaram que apenas 1,4\% nunca atuou na profissão, elencando, além da reduzida remuneração, a ausência de oferta de trabalho na área da pretendida. Constataram ainda que 9,1\% deles exerciam atividades fora do campo da Psicologia (transição de profissão). Neste grupo, os principais motivos da não inserção ou abandono estavam fortemente associados à oferta de um emprego melhor e à baixa remuneração da profissão. No entanto, entre os que passaram por transição de profissão, 91,1\% responderam afirmativamente que gostariam de voltar a atuar com a Psicologia. Além desse estudo, a baixa remuneração também foi apontada por Santos et al. (2014) em que os psicólogas/os $(n=85)$ de um município mineiro ganhavam entre três e quatro salários mínimos.

Outro fato diz respeito à inserção de recém-formados no mercado de trabalho (transição universidade-trabalho). Nogueira et al. (2015) constataram que $50 \%$ dos recém-graduados $(n=45)$ de uma instituição de ensino mineira não estavam atuando na profissão, e que grande parte deles se referiram a motivos não identificados e outros por questões particulares, por ter encontrado melhores oportunidades em outra área, por não ter procurado emprego na área ainda ou por não se inte- 


\section{M." INTERACÃO EM PSICOLOGIA}

ressar mais pela profissão. Daqueles que atuavam na profissão, $44 \%$ recebiam até três salários mínimos mensais. Leite et al. (2011), ao analisarem recém-formados $(n=20)$ de uma universidade da Grande São Paulo, verificaram que $85 \%$ estavam exercendo a profissão, no entanto, os salários não eram os almejados. Os resultados do estudo de Malvezzi et al. (2010) mostraram que a proporção dos recém-formados $(n=835)$ que já estava inserida na profissão era de apenas $41,5 \%$ e que os outros justificaram a situação pela falta de oferta de trabalho. No entanto, esta condição se estende à visão de psicólogas/ os considerados mais experientes, quando verificaram alguma crise profissional pela não oferta de perspectiva futura e a baixa remuneração.

Ainda que a percepção sobre a remuneração seja desfavorável, Puente-Palacios et al. (2010) apuraram que a maior parte dos psicólogas/os brasileiras/os [n=1685; 84,5\% (Bastos \& Gondim, 2010)] não pretendia mudar de profissão. 0 interesse de permanecer envolvia a satisfação com o trabalho, a imagem da profissão, o envolvimento com o trabalho e o comprometimento afetivo e normativo com a carreira. CarvaIho (2007) trouxe reflexões semelhantes quando investigou a carreira de psicólogas/os ( $n=290)$ e constatou que a intenção de permanecer na profissão e área de atuação se correlacionaram positivamente com o comprometimento afetivo e aos fatores internos (habilidades, interesses pessoais e vocação) como condicionantes à escolha da profissão.

Outros trabalhos descrevem quais ações e atributos que facilitam o desenvolvimento da carreira de psicólogas/os face às transições. Ainda que o mercado de trabalho seja seletivo para os recém-graduados, Cruz (2016) salienta que psicólogas/os $(n=10)$ que participaram de atividades em empresas juniores em Psicologia do Trabalho enquanto acadêmicos, inseriram-se na profissão com maior segurança e competência, uma vez que desenvolveram diversas aprendizagens, ampliaram o autoconhecimento e as crenças de autoeficácia, criando expectativas mais realistas sobre o trabalho e a definição de interesses profissionais, o que contribuiu para a elaboração de projetos futuros. Malvezzi et al. (2010) observam que os recém-formados, mediante os impasses e exigências do mercado de trabalho, correm para disputar vagas públicas em concursos, realizam novas formações de pós-graduação e buscam empreender seu negócio.

Já Bedin (2010), identificou seis categorias referentes ao estágio de estabelecimento da carreira de psicólogas/os residentes no Rio Grande do Sul $(n=15)$ : networking, desenvolvimento de habilidades, realização profissional, legalização do vínculo de trabalho, preocupação com desempenho profissional e a busca constante por qualificação. Contudo, verificou que muitos participantes atrelavam a fase da estabilização da carreira - estágio evolutivo da carreira da teoria de Donald Super - à obtenção de vínculo formal de trabalho com carteira de trabalho ou trabalho em serviço público. Para Marcondes (2014) não é surpresa essa movimentação, uma vez na sua concepção dirigentes de diversos cursos de graduação em Psicologia não se atentam para a realidade externa à academia e incentivam os alunos a buscarem vagas públicas. Essa posição pode ser questionada, uma vez que há relatos de psicólogas/os que buscam concursos públicos pela estabilidade e segurança nos rendimentos, enquanto constroem suas carreiras. Vislumbrando um contraponto e a possibilidade da/o psicóloga/o empreender, Marcondes (2014) identificou atributos pessoais marcantes naqueles que optaram em empreender em suas carreiras $(n=6)$. 0 referido autor concluiu que a autoeficácia, a criatividade, o conhecimento formal, aproveitar conhecimentos de experiências anteriores e as vivências e influências familiares, além da percepção e da avaliação de oportunidades - pouca concorrência, aumento da demanda, networking, bons resultados anteriores, observar os concorrentes e trazer novidades à população - seriam estratégias que facilitam empreender na Psicologia. Também verificou que eles se consideram realizados profissionalmente, são reconhecidos socialmente e percebem positivamente seus rendimentos financeiros.

Conforme exposto, os estudos acerca da carreira do psicóloga/o podem fomentar avanços científicos e sociais para a compreensão da própria categoria, conferindo possíveis caminhos para maior qualidade dos serviços prestados à população e para a formação profissional em atendimento às novas demandas. Deste modo, este artigo possui dois objetivos: (a) identificar quais são os motivos da transição em uma amostra de psicólogas/os brasileiros que se autodefine em situação de transições na carreira; e (b) conhecer as estratégias de enfrentamento que adotam para lidar com essa condição. Na literatura consultada cujo público-alvo foi psicólogas/os, poucos estudos foram orientados a este enfoque de captar profissionais em processo de transições e descrever por que estão em mudanças e quais caminhos percorrem para se adaptar à nova condição de trabalho. Isso torna a presente investigação uma pesquisa exploratória inicial que visa contribuir com a produção do conhecimento acerca da transição de carreira de psicólogas/os.

\section{MÉTODO}

\section{PARTICIPANTES}

Esse estudo derivou de uma tese de doutorado da primeira autora do artigo com profissionais graduados que se autodeclararam em situações de transições na carreira $(n=533)$, cujo objetivo foi adaptar um instrumento de avaliação de recursos psicológicos de adultos em processo de transições na carreira. A pesquisa online foi direcionada para profissionais de 


\section{M." INTERACÃO EM PSICOLOGIA}

qualquer idade e região do Brasil, divulgada por redes sociais e correio eletrônico, sendo este último direcionado às universidades de todas as regiões do país, solicitando o encaminhamento do link à terceiros com efeito bola de neve. Os psicólogas/os participantes $(n=91)$ foram selecionados para compor a amostra deste estudo. Fez-se uso do banco de dados da pesquisa maior com o propósito de realizar a análise qualitativa das respostas às questões sobre transição na carreira que não foram analisadas na outra pesquisa.

A maioria da amostra de psicólogas/os era mulher (85,7\%), com idade média de 34,84 anos ( $D P=9,48)$ e com alto nível de escolaridade: $7,7 \%$ doutores; $29,4 \%$ mestres; $36,3 \%$ especialistas e $26,4 \%$ graduados. Havia 30,8\% servidores públicos, $22 \%$ profissionais liberais, autônomos ou empresários, 19,8\% trabalhavam em empresas privadas, uma parcela substancial de 14,3\% estava desempregada, 8,8\% eram vinculados à programas de pós-graduação (pesquisadores de mestrado/ doutorado/pós-doutorado) e outros 4,4\% trabalhavam em instituições do terceiro setor. Grande parte, $75,9 \%$, trabalhava diretamente com a Psicologia e a decisão de mudança em $68,13 \%$ deles foi de natureza voluntária. Havia $46,15 \%$ em situação de transições dentro da profissão, 28,57\% em transições de profissão, 13,18\% em transições de postos de trabalho, 12,08\% em transições universidade-trabalho e nenhum em situação de pré-aposentadoria.

\section{INSTRUMENTOS E PROCEDIMENTOS}

No questionário sociodemográfico e profissional havia questões fechadas sobre sexo, idade, escolaridade, natureza do vínculo de trabalho, ocupação atual, quais transições na carreira vivenciava e por quanto tempo atuou na profissão anterior caso estivesse em transição de profissão. Ao final havia duas questões abertas, objetivo do estudo: (a) cite quais motivos o/a fizeram mudar na carreira e (b) cite quais estratégias você vem utilizando ou já utilizou para passar por essa transição na carreira. $O$ estudo foi aprovado pelo Comitê de Ética em Pesquisa da Faculdade de Filosofia, Ciências e Letras da Universidade de São Paulo, CAAE n.39788914.2.0000.5407, conforme as normas da Resolução n 466/12 do Conselho Nacional de Saúde (CNS).

As respostas referentes às questões abertas foram abordadas pela Classificação Hierárquica Descendente (CHD), gerada pelo software de análise textual IRaMuTeQ (Interface de $R$ pour les Analyses Multidimensionnelles de Textes et de Questionnaires). Segundo Camargo e Justo (2013), a CHD permite analisar as raízes lexicais e os contextos em que as classes estão inseridas. Foram processados e analisados os textos dos 91 respondentes, os quais subdividiram-se em dois corpus (Motivos das Transições na Carreira e Estratégias de Enfrentamento das Transições na Carreira). Obteve-se um dendograma de cada corpus com as referidas classes de palavras, sendo desconsideradas as palavras com $\chi 2>3,84$ e $p<0,05$ (Camargo \& Justo, 2013). As palavras das classes foram submetidas a uma análise de conteúdo com respaldo da interpretação pessoal dos pesquisadores em articulação com a literatura sobre transição na carreira.

\section{RESULTADOS E DISCUSSÃO}

\section{MOTIVOS DAS TRANSIÇÕES NA CARREIRA}

O corpus Motivos das Transições na Carreira reteve $64,84 \%$ dos textos analisados, 1695 ocorrências, 658 formas identificadas e 539 lemas. Durante a CHD, o corpus se dividiu por três vezes até ocorrer uma estabilização do conteúdo e contextos das palavras, gerando quatro classes. Estas são ilustradas na Figura 1, compondo seus valores percentuais em relação ao total do corpus analisado, as palavras que compõem as classes e a indicação do grau de significância das palavras que possuíam mais afınidade com a classe, por meio da associação com o qui-quadrado.

Seguindo a ordem de aparecimento das classes, a primeira a ser composta foi a classe 4 , conforme indica a Figura 1, denominada de Remuneração (23,7\% do corpus; 14 segmentos de textos [ST]). Ela revela como motivo frequente das transições a insatisfação com a remuneração da profissão, como verificado em algumas respostas, tais como: "Falta de oportunidades, desvalorização da profissão e baixo salário"; "Passei em concurso público com melhor remuneração e carga horária" e; "[...] baixa remuneração e complexidade do trabalho". Esses resultados corroboram os achados de outros estudos, ou seja, de que os psicólogas/os brasileiros, em geral, são mal pagos, e eles indicam que o abandono da profissão tem sido relacionado às condições de trabalho. Para aqueles que permanecem mesmo diante de baixos salários, a condição propicia o acúmulo de vínculos de trabalho para suprir necessidades financeiras (Bedin, 2010; Heloani et al., 2010; Leite et al., 2011; Nogueira et al., 2015; Santos et al., 2014).

Na classe 3, Qualidade de Vida (23,7\% do corpus; 19 ST), o equilíbrio da esfera pessoal, familiar e profissional pesou nas decisões. Super (1980) já apontava que no desenvolvimento da carreira ao longo do ciclo vital é esperado em algum momento que haja um deslocamento da saliência do papel do trabalho para outros papéis relativos à família e a vida social, afinal a carreira é constituída não apenas do trabalho, mas da união dele com outras esferas da vida. Alguns trechos demonstraram esses conteúdos: "[...] qualidade de vida e trabalhar ao lado do meu marido" e "[...] qualidade de vida e possibilidades de ganhos financeiros". A razão das transições em busca por mais tempo com a família e por fatores da vida pessoal converge com outras realidades profissionais e contextos investigados 


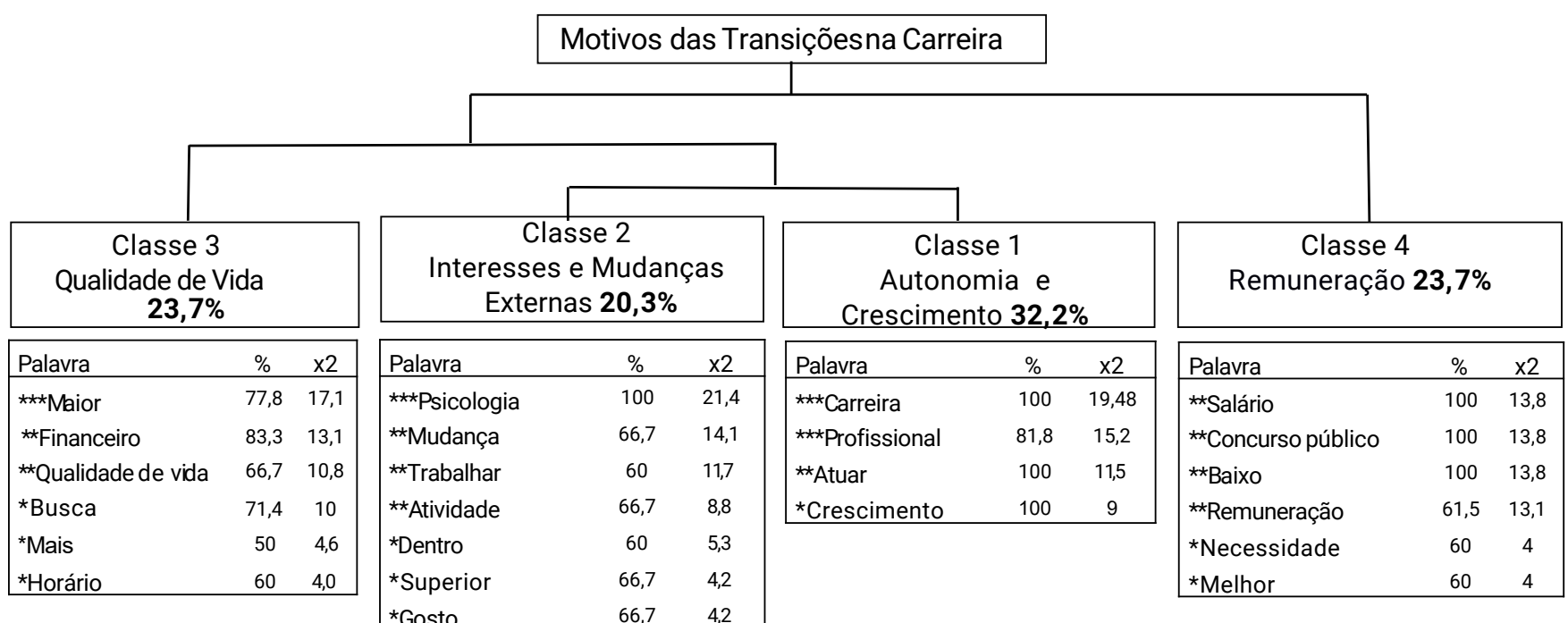

Figura 1. CHD do corpus Motivos das Transições na Carreira Nota: $* \mathrm{p}<0,05 ; * \star \mathrm{p}<0,01 ; * * * \mathrm{p}<0,0001$

(Cabrera, 2007; Gomes \& Teixeira, 2000; Kilimnik \& Rodrigues, 2000; Quishida \& Casado, 2009; Uvaldo, 2010).

Foi observado que a classe 2, Interesses e Mudanças Externas (20,3\% do corpus; 12 ST), agrupou dois segmentos de escolhas para as mudanças. Psicólogas/os que desejavam conhecer outras áreas da profissão e/ou que almejavam outras atividades profissionais, como Artes, Direito, Estilismo, Comércio e Vendas, entre outras, expressos em registros como: "Eu gosto de Psicologia, mas não amo tanto quanto amo trabalhar com Produção Criativa". E houve aqueles que apontaram a influência de fatores externos, como ajustes na empresa e piora do clima organizacional, fim de contrato de trabalho, não encontrar emprego na área de especialidade e ter que acompanhar a família em mudança residencial, como verificado em algumas respostas como as descritas a seguir: "Trabalhava com $\mathrm{RH}$ [recursos humanos] e fui desligada da instituição" e "[...] nunca consegui uma posição na área da Psicologia que eu realmente queria trabalhar". Os efeitos negativos do mundo corporativo compõem uma gama de motivos que envolvem mudanças nas trajetórias da carreira, como a pressão, sobrecarga, estresse, conflitos e ambientes que inviabilizam espaço para expressar a criatividade (Carless \& Arnup, 2011; Gomes \& Teixeira, 2000), assim como demissões em massa (Kilimnik \& Rodrigues, 2000). Praticamente um terço dos psicólogas/os declarou transições de natureza involuntária na época da coleta de dados (2016), quando o país registrava a taxa de $12 \%$ de desemprego.

$\mathrm{Na}$ última classe formada, classe 1, Autonomia e Crescimento (32,2\% do corpus; $14 \mathrm{ST})$, a autonomia se referiu aos benefícios de gerir horários, obter progressos financeiros e poder distanciar-se de influências e pressões políticas externas, tão presentes nos ambientes empresariais e no serviço público. A transição também implicaria em ganhos secundários, como a escolha do modo de trabalhar, selecionando atividades que tragam mais identificação, reconhecimento e crescimento profissional, como analisados nos seguintes trechos: "[...] desenvolvimento profissional, terei mais controle do meu trabalho, horários, pela instabilidade do mercado, ... fazer algo que eu esteja identificada ... alcançar reconhecimento [...]"; "[...] a carreira do psicóloga/o dentro do RH é muito mais política do que de apoio, desenvolvimento, aprendizado" e; "[...] pelas interferências de terceiros no serviço em face de motivos quase sempre políticos [...]". Tais motivos convergem com as vantagens relatadas por psicólogas/ os que optaram por se tornar empreendedores (Marcondes, 2014). Compreende-se que busca de autonomia e crescimento são fatores frequentes que impulsionam as pessoas para o redirecionamento da carreira considerando as mais diversas profissões, conforme concluíram Cabrera (2007), Chudzikowski et al. (2009), Donohue (2007), Joia e Mangia (2017) e Uvaldo (2010), entre outros, não se delimitando, portanto, à classe das/os psicólogas/os.

\section{ESTRATÉGIAS DE ENFRENTAMENTO DAS TRANSIÇÕES NA CARREIRA}

O corpus Estratégias de Enfrentamento das Transições na Carreira foi constituído por 91 textos, com aproveitamento de $57,14 \%$ deles. Emergiram 1887 ocorrências, 735 formas identificadas e 579 lemas. A CHD dividiu o corpus e, após quatro partições, apresentou a produção de cinco classes de palavras, as 


\section{M." INTERACÃO EM PSICOLOGIA}

quais foram submetidas ao mesmo protocolo de análise mencionado no corpus anterior e estão apresentadas na Figura 2.

A Figura 2 aponta que a primeira classe gerada, classe 1, Estudos, Parcerias e Planejamento (19,23\% do corpus; 10 ST), reuniu como principal estratégia de enfrentamento das transições o ato de estudar. Incluíram o estudo por conta própria e/ou participar de cursos de especialização, direcionados para melhor atuação na referida especialidade e/ou para obter aprovação em concursos públicos. Para Yamamoto et al. (2010) a busca pelo estudo não é uma surpresa no caso dos psicólogas/os, pois detectaram que $60,3 \%$, da amostra nacional de Bastos e Gondim (2010), tinham envolvimento com alguma forma de pós-graduação. Fato que foi detectado e perceptível para profissionais em transições universidade-trabalho, que a graduação não prepararia o suficiente para o exercício profissional, assim é preciso estar constantemente se aprimorando, atualizando e buscando especializações para inserção no mercado de trabalho ou aprovação em concursos públicos (Malvezzi et al., 2010; Nogueira et al., 2015). A busca por informações e conhecimentos têm sido uma estratégia unânime também em outros contextos sociais e profissionais (Baruch \& Quick, 2009; Faulkner, 2007; Muja \& Appelbaum, 2012; Nooney et al., 2010), além de ser um elemento norteador em processos de Aconselhamento de Carreira (Chen, 2005; Magalhães, 2011). Como uma das principais competências requeridas para o século XXI é "aprender a aprender", o estudo para a atualização constante é cada vez mais necessário e, nesse sentido, os psicólogas/os estão se preparando para os desafios em um mundo volátil, incerto, complexo e ambíguo.
Ainda na Classe 1 encontrou-se a ação envolta ao estabelecimento de parcerias, além do planejamento da transição por intermédio profissional, como a psicoterapia e auxílio do coaching. Os trechos seguintes demonstram esse cenário: "Me organizei estudando e prestando concursos, psicoterapia."; "Estou estudando para concursos, reformulando o currículo [...]." e; "[...] fiz coaching, fiz cursos [...] pesquisei muitas possibilidades e iniciei parcerias." Fato que remonta aos achados de Kilimnik e Rodrigues (2000), quando psicólogas/ os demitidos em massa se reorganizaram formando parcerias, atuando como consultores associados e se vinculando às cooperativas de serviços, além da necessidade de terem mobilizado aspectos do self como a autoconfiança e terem elaborado um planejamento para a carreira. Outros estudos reforçam a importância do planejamento e do coping focado no problema e na emoção (Cohen-Scali, 2015; Krumboltz, et al., 2013; Veloso \& Dutra, 2011).

$\mathrm{Na}$ segunda classe composta, classe 5, Mercado e Networking (19,23\% do corpus; $10 \mathrm{ST}$ ) leituras e análises acerca do dinamismo do mercado de trabalho e o uso do networking profissional e pessoal foram descritas como a seguir: "Muito diálogo com centenas de profissionais e pessoas ligadas [...]"; "[...] muito contato com os colegas do trabalho atual, estudos e leituras." e; "[...] qualificação nos estudos, aprimoramento e leituras sobre o mercado de trabalho." O fortalecimento das redes de contatos com profissionais, colegas e familiares, de acordo com Anderson et al. (2012), insere-se na dimensão suporte, evidenciando estratégias de enfrentamento por meio da ativação de canais de comunicação que possibilitam a indicação para trabalhos e o compartilhamento de informa-

\begin{tabular}{|c|c|c|c|c|c|c|c|c|c|c|c|c|c|c|}
\hline & & & Estraté & ias $d$ & e En & entamento d & Tra & าsiçõ & s na Carre & & & & & \\
\hline & & & & & & & & & & & & & & \\
\hline $\begin{array}{l}\text { Class } \\
\text { Estudos, } \mathrm{P} \\
\text { Planejamer }\end{array}$ & $\begin{array}{l}1 \\
\text { cerias } \\
19,2\end{array}$ & & $\begin{array}{r}\text { Clas } \\
\text { Pesquisa } \epsilon \\
17,\end{array}$ & $\begin{array}{l}\text { e } 4 \\
\text { Docê } \\
\%\end{array}$ & ncia & $\begin{array}{r}\text { Class } \\
\text { Capacitação } \\
\mathbf{1 9 , 2}\end{array}$ & $\begin{array}{l}3 \\
\text { ofiss } \\
6\end{array}$ & onal & $\begin{array}{r}\text { Cla } \\
\text { Novas Ex } \\
25\end{array}$ & 2 têno & & $\begin{array}{r}\text { Class } \\
\text { Mercado e } \Lambda \\
19,2\end{array}$ & $\begin{array}{l}5 \\
\text { twork }\end{array}$ & ing \\
\hline Palavra & $\%$ & $x^{2}$ & Palavra & $\%$ & $x^{2}$ & Palavra & $\%$ & $x^{2}$ & Palavra & $\%$ & $x^{2}$ & Palavra & $\%$ & $x^{2}$ \\
\hline${ }^{* * *}$ Estudar & 100 & 23,2 & ***Doutorado & 100 & 20,7 & ***Participar & 100 & 23,2 & ***Área & 61 & 19,1 & 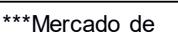 & 100 & 18,2 \\
\hline${ }^{* * *}$ Possibilidade & 100 & 23,2 & *** Pesquisa & 80 & 15,2 & ***Especialização & 83 & 18 & ${ }^{* \star}$ Graduação & 80 & 8,9 & trabalho & & \\
\hline ***Transição & 100 & 18,2 & **Projeto & 57 & 9 & ${ }^{* *}$ Curso & & 13 & $\begin{array}{l}\text { ** Realizar } \\
\text { **Buscar }\end{array}$ & 75 & $\begin{array}{l}5,8 \\
52\end{array}$ & ***Estudo & 83 & 18 \\
\hline${ }^{* *}$ Concurso & 80 & 13,1 & **Estar & 50 & 7 & & & & & & & **Leitura & $\begin{array}{l}67 \\
60\end{array}$ & $\begin{array}{l}9,8 \\
5,9\end{array}$ \\
\hline **Pesquisar & 60 & 5,9 & ${ }^{* *}$ Mudar & 67 & 5,4 & & & & & & & ${ }^{* \star}$ Rede contatos & 67 & 4,6 \\
\hline **Passar & 67 & 4,6 & & & & & & & & & & **Ano & $\begin{array}{l}67 \\
67\end{array}$ & $\begin{array}{l}4,6 \\
4,1\end{array}$ \\
\hline
\end{tabular}

Figura 2. CHD do corpus Estratégias de Enfrentamento das Transições na Carreira Nota: $* \mathrm{p}<0,05 ; * \star \mathrm{p}<0,01 ; * \star * \mathrm{p}<0,0001$ 


\section{M." INTERACÃO EM 2. PSICOLOGIA}

ções sobre o mercado de trabalho e experiências profissionais. Além de ser uma estratégia recorrente (Bendassolli et al., 2015; Murtagh et al., 2011), Muja e Appelbaum (2012) destacam, ainda, o papel da interação com o networking em razão de diversas oportunidades, sobretudo as mais estratégicas, serem preenchidas por intermédio de indicações.

Já na próxima classe, classe 4, Pesquisa e Docência (17,3\% do corpus; 9 ST), as estratégias envolveram ampliar a rede de contatos com pesquisadores e docentes, a vinculação a grupos de pesquisa, participação em congressos, desenvolvimento de projetos de pesquisa e preparação para concursos públicos na carreira docente, como analisado em trechos: "Persistir no processo de formação, concluindo o curso de doutorado e sendo aprovada em concurso público federal."; "Fiz o mestrado e estou desenvolvendo projeto para o doutorado [...]." e; "[...] me vinculando às pesquisas e contatos de pesquisadores." Estas ações indicam um direcionamento àqueles que tem por objetivo a carreira docente e a pesquisa. É curioso questionar quais seriam as razões desta escolha. Seria pelo fato de que a remuneração docente é uma das maiores identificadas na profissão (Heloani et al., 2010)? Seria em decorrência da ampliação dos cursos de graduação em Psicologia (Travassos \& Mourão, 2018), que tornou o campo docente um atrativo gerador de empregos? Seria um caminho alternativo, uma vez que o mercado de trabalho está restrito? Seria uma forma de continuar estudando ou uma decisão pautada exclusivamente nos interesses vocacionais? Segundo Gómez (2006), psicólogas/os docentes $(n=11)$ de Santa Catarina direcionaram a carreira à academia pelo interesse vocacional na docência, pela vontade de continuar pesquisando, por se qualificar para ampliar campos de atuação e por constatar melhor retorno financeiro que em outros campos de trabalho.

Os textos que compuseram a classe 3, Capacitação Profissional (19,23\% do corpus; $10 \mathrm{ST})$, visavam à participação e à realização de capacitações em diversas modalidades (cursos livres, eventos, feiras, congressos, treinamentos, aperfeiçoamentos e especializações) como meio de melhor capacitar para o exercício prático da Psicologia e/ou das novas atividades profissionais, como: "[...] participar de eventos da nova profissão como congresso, conhecer e conviver com outros profissionais da outra carreira e pesquisar sobre o campo da nova atuação."; "Aprendi sobre venda, comércio e também participo de treinamento"; e; "[...] formação em terapia de traumas [...]." Como a Psicologia possibilita um leque de áreas de atuação as quais, segundo Tosi e Botomé (2003) e Rechtman e Bock (2019), vem sendo há décadas profundamente transformadas com a aproximação das causas e movimentos sociais e de políticas públicas, presume-se que os psicólogas/ os percebam a necessidade de buscar conhecimentos para empregar no exercício profissional. E, ao considerar a baixa remuneração da profissão, Heloani et al. (2010) sugerem que
Marlize Paulo da Silva e Lucy Leal Melo-Silva

possuir dois ou três vínculos de trabalho em diferentes áreas da Psicologia (e/ou fora dela) indica ser uma realidade brasileira. Quase metade desta amostra declarou estar em transições dentro da profissão e esta situação exige conhecimentos, dedicação e preparo profissional, especialmente quanto aos novos saberes e práticas da profissão que ainda estão em processo de transformação (Silva \& Alexandre, 2019). Portanto, mediante este cenário, justifica-se porque os psicólogas/ os primaram também pelas capacitações profissionais.

E na última classe composta, classe 2, Experiências Novas (25\% do corpus; $13 \mathrm{ST}$ ), os profissionais apostaram em experimentar novos trabalhos em diferentes áreas/profissões, assumir contratos de trabalhos temporários, para testagem e verificação dos interesses vocacionais e adaptações, engajar-se em trabalhos voluntários na nova área e realizar estágios, sendo este último em caso de cursar nova graduação. Alguns exemplos assinalados: "[...] conversas com pessoas de outras profissões, leituras, trabalho temporário."; “[...] aprender e me desenvolver na área de vendas [...] iniciar um curso para prova de habilitação da nova profissão." e; "[...] buscar experiências relacionadas à nova área para atuação voluntária e como estágio [...]". Veloso e Dutra (2011) detectaram que desenvolver flexibilidade entre empregos, trabalhos e serviços de diversos vínculos auxiliam na aproximação de novas experiências e agregam mais valor à bagagem profissional, assim como Teixeira e Gomes (2004), Monteiro e Almeida (2015) e Cruz (2016) enfatizaram o papel relevante de atividades extraclasse na academia para facilitar a inserção profissional. Nesta classe compreende-se que tais ações preconizam transições graduais, de modo que, quando estiverem mais certos e ajustados quanto à nova escolha, podem desligar-se das atividades anteriores. As conversas com profissionais de diversos ramos, a ampliação do networking direcionada à nova atividade profissional e a realização de cursos variados também foram reportadas, mas em menor frequência. Transições como deixar a Psicologia e estudar Medicina, Direito, ou ainda migrar para área comercial, imobiliária, de ilustração e da moda, envolvem o desenvolvimento de novas aprendizagens, voltando à etapa da exploração inicial da carreira (Super, 1980). Para Anderson et al. (2012) a situação pode implicar na dependência financeira de familiares e na redução do custo de vida temporariamente, contando fortemente com a dimensão do suporte e, além disso, conforme recomendam Chen (2005) e Heppner (1998), desenvolver as crenças do self, como a autoeficácia, autoconfiança, locus de controle interno e, como descrito por um participante "Começarei a fazer o curso de Medicina, muito estudo e uma ótima dose de paciência!", trabalhar a prontidão e a resistência psicológica para alcançar objetivos em médio e/ou longo prazo, atitudes fundamentais para lidar com as transições na carreira. 


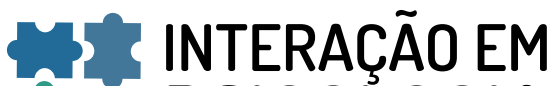 ET PSICOLOGIA}

\section{CONSIDERAÇÕES FINAIS}

Este estudo visou descrever o que motivou uma amostra de psicólogas/os brasileiros a mudarem suas trajetórias profissionais e em como gerenciam a transição. Os principais resultados se equiparam aos achados de outras investigações, nacionais e internacionais, e não restritos à profissão da/o psicóloga/o. O fato de as/os psicólogas/os denotarem insatisfação com a remuneração é algo recorrente (Bastos \& Gondim, 2010; Leite et al., 2011; Santos et al., 2014; Nogueira et al., 2015) e isso foi comprovado neste estudo como o primeiro gatilho que as/os levam às mudanças em suas carreiras. Segundo Heloani et al. (2010) essa realidade é um dilema para muitos, pois declaram que se tivessem melhores salários, gostariam de voltar a trabalhar na profissão. É possível que esse cenário as/os propicie a terem mais de um vínculo de trabalho, gerando sobrecarga, estresse e interferência na vida pessoal e familiar. Talvez e, não por acaso, pode-se pensar se há alguma inferência dessa situação em estudos posteriores, já que a busca por maior qualidade de vida, autonomia e crescimento profissional foram outros motivos revelados pelas/os participantes. Os efeitos do mundo do trabalho precarizado, do desemprego e da economia em recessão puderam ser constatados nas respostas de que algumas transições também se deram face à reestruturação organizacional, provocando demissões e/ou piora do clima organizacional, afınal, quase $31 \%$ das/os participantes encontravam-se em transições involuntárias.

Neste âmbito ações em nível macro e micro podem ser elaboradas, desejando reduzir o número daqueles que abandonam a profissão e, para os que se mantenham nela, obtenham melhores condições de trabalho e qualidade dos serviços prestados. Cabe às associações profissionais e aos conselhos envidar esforços no estabelecimento e fiscalização do piso salarial, da jornada de trabalho semanal e valorização da profissão no mercado de trabalho. E, cabe às/aos psicólogas/os se posicionarem frente às situações de precarização que tendem a desvalorizar a profissão, questionando e reivindicando melhores condições de trabalho. Porém, a questão é: em tempos de desemprego haveria espaço para esse tipo de reinvindicação? Esse é o desafio dos trabalhadores de todas as categorias em um contexto de desaquecimento da economia e de pandemia. Porém, essa situação requer a/o psicóloga/o para intervir em questões de promoção, prevenção e tratamento em saúde mental.

Os meios pelos quais as/os participantes deste estudo enfrentam as mudanças na trajetória da carreira encontram respaldo na literatura científica e nos princípios teóricos-metodológicos de processos de Aconselhamento de Carreira com adultos (Anderson et al., 2012; Chen, 2005; MagaIhães, 2011). Neste sentido, foram descritas estratégias de estudar, estabelecer parcerias, ativar e ampliar o networking, analisar o mercado de trabalho e desenvolver-se em direção a novos interesses vocacionais, o que permite concluir que os psicólogas/os buscaram estratégias que envolviam um nível de comprometimento e responsabilidade pelo planejamento da carreira, revelando locus de controle interno e sugerindo algum nível de autoeficácia para a adaptabilidade. No entanto, o cenário de transformações na profissão e de instabilidades político-econômicas traz o desafio de desenvolver outros meios de enfrentamento que não se limitem às ações individuais, contrapondo as narrativas que responsabilizam o próprio indivíduo pelo sucesso/insucesso da trajetória de sua carreira. Se por um lado é interessante valorizar o indivíduo pelo seu sucesso, por outro lado, na situação de fracasso o profissional ficaria com um ônus muito grande quando os fatores contextuais (formação acadêmica, economia e mercado de trabalho) constituem variáveis relevantes. Assim, nessa interação indivíduo (interesse vocacional) e sociedade (mundo do trabalho) as pessoas constroem a vida pessoal e a carreira. Portanto, lidar com transições na carreira torna-se rotina na contemporaneidade, o que requer entender as mudanças no mundo do trabalho e desenvolver estratégias para o enfrentamento nas transições, incluindo a situação de ausência de trabalho e renda. Uma perspectiva contemporânea de trabalho é a de realização de vários projetos ao longo da vida/carreira.

Quanto à dimensão macrossocial, pondera-se a alternativa de investir durante a graduação em disciplinas que se preocupem com a gestão da carreira, o mercado de trabalho, o empreendedorismo, o uso das tecnologias para trabalho à distância, visando melhor preparação para gerenciar os momentos de mudanças e para ampliar a visão do mundo do trabalho e do trabalho da/o psicóloga/o. Outra medida, que atualmente existe em algumas universidades do país, e que se sugere ampliação e maior visibilidade, é a oferta de serviços de Aconselhamento de Carreira aos acadêmicos e, sobretudo, aos não acadêmicos, com auxílio desde a indecisão da escolha profissional até o redirecionamento de adultos em transições em meio da carreira. Isto posto, outra frente de ação é a criação de programas governamentais destinados ao trabalhador brasileiro, de todos os níveis educacionais e profissões, incluindo a do psicóloga/o, que visem a educação para a carreira ao longo da vida. Para além da Orientação Profissional e de Carreira em contextos educativos, é preciso estimular políticas públicas para a oferta de serviços no âmbito do trabalho e da geração de renda, com vistas a auxiliar os trabalhadores no desenvolvimento de suas carreiras.

Por fim, nota-se que este estudo apresenta ao menos duas limitações. Os dois corpus foram compostos por textos curtos, que variaram de uma a três linhas, dificultando a proporção de aproveitamento deles para a condução da CHD, 


\section{M." INTERACÃO EM PSICOLOGIA}

conforme recomendam Camargo e Justo (2013). Outro ponto refere-se a pequena amostra de psicólogas/os e que, por uma das fontes de acesso aos participantes ter sido o mailing de universidades, parte deles inseria-se no meio acadêmico, propiciando alguns vieses, fato expresso pela criação da classe de enfrentamento das transições Docência e Pesquisa.

Destarte, os achados serviram para enriquecer o campo de debates da Orientação Profissional e de Carreira e de estudos acerca da carreira da/o psicóloga/o brasileiro. No entanto, compreende-se que muitos questionamentos ainda precisam ser explorados para melhor interpretação do fenômeno das transições na carreira de psicólogas/os, preconizando estas indagações e alavancando o campo de estudos sobre desenvolvimento da carreira e as transições aspiradas pelos psicólogas/os brasileiros. Além disso, sugerem-se investigações sobre transições com outras amostras de diferentes profissões, a fim de verificar o que seria universal e o que seria específico. E, finalizando cabe destacar que as transições são e continuarão sendo frequentes no século $\mathrm{XXI}$, um cenário com complexas questões políticas, tecnológicas, sociais e existenciais.

\section{CONTRIBUIÇÃO DE CADA AUTOR}

Certificamos que todos os autores participaram suficientemente do trabalho para tornar pública sua responsabilidade pelo conteúdo. A contribuição de cada autor pode ser atribuída como se segue: M.P.S. e L.L.M.S. contribuíram para a conceitualização, investigação e visualização do artigo; M.P.S. fez a coleta de dados e a redação inicial do artigo (rascunho) e M.P.S e L.L.M.S. são os responsáveis pela redação final (revisão e edição).

\section{DECLARAÇÃO DE CONFLITOS DE INTERESSES}

Os autores declaram que não há conflitos de interesse no manuscrito submetido [comitê de ética da Faculdade de Filosofia, Ciências e Letras da Universidade de São Paulo, CAAE n.39788914.2.0000.5407].

\section{REFERÊNCIAS}

Anderson, M. L., Goodman, J., \& Schlössberg, N. K. (2012). Counseling adults in transitions: Linking Schlössberg's theory with practice in a diverse world (4th ed.). Springer Publishing Company.

Baruch, Y., \& Quick, J. Q. (2009). Setting sail in a new direction. Personnel Review, 38(3). https://doi. org/10.1108/00483480910943331.
Bastos, A. V. B., \& Gomide, P. I. C. (1989). O Psicólogo brasileiro: Sua atuação e formação profissional. Psicologia: Ciência e Profissão, 9(1), 06-15.

Bastos, A. V. B., \& Gondim, S. M. G. (2010). O trabalho do psicólogo no Brasil: Um exame à luz das categorias da Psicologia organizacional e do trabalho. Artmed.

Bedin, L. M. (2010). Desenvolvimento de carreira em psicólogos: Tarefas evolutivas do estágio de desenvolvimento [Dissertação de Mestrado, Universidade Federal do Rio Grande do sul]. Repositório Digital UFRGS. https://www.lume.ufrgs.br/bitstream/handle/10183/26082/000756187.pdf?sequence $=1$.

Bendassolli, P. F., Coelho-Lima, F., Carlotto, M. S., Nussele, F. S., \& Ferreira, I. M. (2015). Estratégias utilizadas pelos trabaIhadores para enfrentar o desemprego. Revista Colombiana de Psicología, 24(2), 347-362. https://doi.org/10.15446/ rcp.v24n2.44416.

Cabrera, E. F. (2007). Opting out and opting in: Understanding the complexities of women's career transitions. Career Development International, 12(3), 218-237. https://doi. org/10.1108/13620430710745872

Camargo, B. V., \& Justo, A. M. (2013). IRAMUTEQ: Um software gratuito para análise de dados textuais. Temas em Psicologia, 21(2), 513-518. http://doi.org/10.9788/TP2013.2-16

Carless, S. A., \& Arnup, J. L. (2011). A longitudinal study of the determinants and outcomes of career change. Journal of Vocational Behavior, 78(1), 80-91. http://doi.org/10.1016/j. jvb.2010.09.002

Carvalho, T. A. T. (2007). A escolha e o comprometimento com a profissão/carreira: Um estudo entre psicólogos [Dissertação de Mestrado, Universidade Federal da Bahia]. Repositório Institucional Kroton. https://repositorio.pgsskroton. com/handle/123456789/19487.

Retirada referência do CFP

Chen, C. P. (2005). Understanding career chance. International Journal for Educational and Vocational Guidance, 5(3), 251270. http://doi.org/10.1007/s10775-005-3600-7.

Chudzikowski, K., Demel, B., Mayrhofer, W., Briscoe, J. P., Unite, J., Bogićević M. B., Hall, D. T., Las Heras, M., \& Shen, Y., Zikic, J. (2009). Career transitions and their causes: A country-comparative perspective. Journal of Occupational and Organizational Psychology, 82(4), 825-849. http://doi. org/10.1348/096317909X474786

Cohen-Scali, V. (2015). Career transitions after a long experience as trade union officer: A qualitative study. International Journal for Educational and Vocational Guidance, 16, 405-423. https://doi.org/10.1007/s10775-015-9319-1.

Conselho Federal de Psicologia. (2004). Pesquisa de opinião com Psicólogos inscritos no Conselho Federal de Psicologia. http://site.cfp.org.br/wp-ontent/uploads/2005/05/Pesquisa_IBOPE.pdf. 


\section{H MTERAC̄OOEM IT PSICOLOGIA}

Cruz, K. O. (2016). Estágio em empresa júnior e carreiras de estudantes de Psicologia: Das práticas do psicólogo às expectativas para o futuro profissional [Dissertação de Mestrado, Universidade Federal de Santa Catarina]. Repositório Institucional UFSC. https://repositorio.ufsc.br/xmlui/handle/123456789/168027.

Donohue, R. (2007). Examining career persistence and career change intent using the career attitudes and strategies inventory. Journal of Vocational Behavior, 70, 259-276. http://doi.org/10.1016/j.jvb.2006.12.002

Duarte, M. F.; \& Silva, A. L. (2013). A reconstrução da carreira em ambientes de trabalho em transformação. Organizações \& Sociedade, 67, 735-751. https://doi.org/10.1590/ S1984-2302013000400009

Faulkner, L. R. (2007). Personal reflections on a career of transitions. The Journal of the American Academy of Psychiatry and the Law, 35(2), 253-9. http://jaapl.org/content/jaapl/35/2/253.full.pdf

Gomes, W. B., \& Teixeira, M. A. P. (2000). Autonomous career change among professionals: An empirical phenomenological study. Journal of Phenomenological Psychology, 31, 78-96. https://doi.org/10.1163/156916200746265

Gómez, S. G. O. (2006). Análise do processo de decidir sobre a carreira profissional de psicólogos docentes universitários [Dissertação de Mestrado, Universidade Federal de Santa Catarina]. Repositório Institucional UFSC. https://repositorio.ufsc.br/handle/123456789/88769

Heloani, R., Macêdo, K. B., \& Cassiolato, R. (2010). O exercício da profissão: Características gerais da inserção profissional do psicólogo. In A.V.B. Bastos, \& S. M. G. Gondim (Orgs.). 0 trabalho do psicólogo no Brasil: Um exame à luz das categorias da Psicologia organizacional e do trabalho. Artmed.

Heppner, M. J. (1998). The career transitions inventory: Measuring internal resources in adulthood. Journal of Career Assessment, 6(2), 135-145. https://doi. org/10.1177/106907279800600202

Joia, L. A., \& Mangia, U. (2017). Career transition antecedents in the information technology area. Information Systems Journal, 27, 31-57. http://doi.org/10.1111/isj.12087

Kilimnik, Z. M.; \& Rodrigues, S. B. (2000). Trajetórias, transições e âncoras de carreiras: Um estudo comparativo e longitudinal com profissionais em Recursos Humanos. Organizações \& Sociedade, 7(17), 145-171. https://doi. org/10.1590/S1984-92302000000100012

Krumboltz, J. D., Foley, P. F., \& Cotter, E. W. (2013). Applying the Happenstance Learning Theory to involuntary career transitions. The Career Development Quarterly, 61(1), 1526. http://doi.org/10.1002/j.2161-0045.2013.00032.x
Leite, W. R., Andreatta, K. M. F., Durães, R. B., Cozza, H. F. P., \& Cruces, A. V. V. (2011). Análise das expectativas do Psicólogo recém-formado. Encontro Revista de Psicologia, 14(21), 105-125 http://pepsic.bvsalud.org/scielo.php?script=sci_nlinks\&re$f=3139399$ \&pid=S1982-1247201500010000600008\&lng=pt.

Lhullier, L. A. (2013). Quem é a psicóloga brasileira? Mulher, Psicologia e Trabalho. Conselho Federal de Psicologia. https://site.cfp.org.br/wp-content/uploads/2013/07/ Quem_e_a_Psicologa_brasileira.pdf.

Magalhães, M. O. (2011). Quinta demanda-chave para a Orientação Profissional: Como ajudar o indivíduo a entender e enfrentar as múltiplas transições em sua carreira? Enfoque transicional. In: M. A. Ribeiro \& L. L. Melo-Silva (Orgs.). Compêndio de Orientação Profissional e de Carreira: Perspectivas históricas e enfoques teóricos clássicos e modernos (Vol. 1). Vetor.

Malvezzi, S., Souza, J. A. J., \& Zanelli, J. C. (2010). Inserção no mercado de trabalho: Os psicólogos recém-formados. In A.V.B. Bastos, \& S. M. G. Gondim (Orgs.). O trabalho do psicólogo no Brasil: Um exame à luz das categorias da Psicologia organizacional e do trabalho. Artmed.

Marcondes, R. C. (2014). Entre buscar oportunidades e obter reconhecimento: Comportamento empreendedor de psicólogos em sua trajetória profissional [Dissertação de Mestrado, Universidade Federal de Santa Catarina]. Repositório Institucional UFSC. https://repositorio.ufsc.br/xmlui/ handle/123456789/129293.

Mazer, S. M., \& Melo-Silva, L. L. (2010). Identidade profissional do psicólogo: Uma revisão da produção científica no Brasil. Psicologia: Ciência e Profissão, 30(2), 276-295. https:// doi.org/10.1590/S1414-98932010000200005.

Monteiro, S., \& Almeida, L. S. (2015). The relation of career adaptability to work experience, extracurricular activities, and work transition in Portuguese graduate students. Journal of Vocational Behavior, 91, 106-112. http://doi.org/10.1016/j.jvb.2015.09.006.

Referência retirada

Muja, N., \& Appelbaum, S. H. (2012). Cognitive and affective processes underlying career change. Career Development International, 17(7), 683-701. https://doi. org/10.1108/13620431211283814.

Murtagh, N., Lopes, P. N., \& Lyons, E. (2011). Decision making in voluntary career change: Another than rational perspective. The Career Development Quarterly, 59(3), 249-263. http://doi.org/10.1002/j.2161-0045.2011.tb00067.x.

Nogueira, T. G., Andrade, I. B. M., Souza, K. G. M., \& Soares, W. C. (2015). Empregabilidade do psicólogo: Análise da percepção de alunos, ex-alunos, professores universitários e selecionadores. Psicologia em Pesquisa, 9(1), 40-49. https://doi.org/10.5327/Z1982-1247201500010006. 


\section{INTERACÃO EM LF. PSICOLOGIA}

Nooney, J. G., Unruh, L., \& Yore, M. M. (2010). Should I stay or should I go? Career change and labor force separation among registered nurses in the U.S. Social Science \& Medicine, 70(12), 1874-1881. https://doi.org/10.1016/j.socscimed.2010.02.037.

Peake, S., \& McDowall, A. (2012). Chaotic careers: A narrative analysis of career transition themes and outcomes using chaos theory as a guiding metaphor. British Journal of Guidance \& Counselling, 40(4), 395-410. http://doi.org/10.108 $0 / 03069885.2012 .704350$

Puente-Palacios, K., Abbad, G. S., \& Martins, M. C. F. (2010). Imagem da profissão e perspectivas futuras de mudança. In A.V.B. Bastos, \& S. M. G. Gondim (Orgs.). O trabalho do psicólogo no Brasil: Um exame à luz das categorias da Psicologia organizacional e do trabalho. Artmed.

Quishida, A., \& Casado, T. (2009). Adaptação à transição na carreira na meia-idade. Revista Brasileira de Orientação Profissional, 10(2), 81-92. http://pepsic.bvsalud.org/pdf/ rbop/v10n2/v10n2a09.pdf.

Rechtman, R., \& Bock, A. M. B. (2019). Formação do psicólogo para a realidade brasileira: Identificando recursos para atuação profissional. Psicologia: Teoria e Pesquisa, 35, e3551. https://doi.org/10.1590/0102.3772e3551.

Ribeiro, M. A., \& Melo-Silva, L. L. (2011). Compêndio de Orientação Profissional e de Carreira: Perspectivas históricas e enfoques teóricos clássicos e modernos (Vol. 1). Vetor.

Rigotti, T., Korek, S., \& Otto, K. (2014). Gains and losses related to career transitions within organizations. Journal of Vocational Behavior, 84(2), 177-187. http://doi.org/10.1016/j. jvb.2013.12.006.

Santos, K. R., Monteiro, L. G., Torres, M. L. C., Sousa, L. G., \& Coelho, A. R. (2014). Perfil dos psicólogos inscritos na Subsede Leste do CRP-04. Psicologia: Ciência e Profissão, 34(4), 864-878. https://doi.org/10.1590/1982-370000162013.

Savickas, M., Nota, L., Rossier, J., Dauwalder, J-P., Duarte, M. E., Guichard, J., Soresi, S., Van Esbroeck, R., \& Van Vianen, A. (2009). Life designing: A paradigm for career construction in the 21st Century. Journal of Vocational Behavior, 75(3), 239-250. https://doi.org/10.1016/j.jvb.2009.04.004

Schölssberg, J., Walters, R., \& Goodman, P. (1995). Counseling adults in transition: Linking theory with practice. Harper \& How.

Silva, R. B., \& Alexandre, A. C. S. (2019). Políticas sociais e subjetividade: Discussões a partir do contexto neoliberal. Psicologia em Pesquisa, 13(1), 1-11. https://doi. org/10.24879/2018001200300478.
Super, D. E. (1980). A life-span, life-space approach to career development. Journal of Vocational Behavior, 16, 282-298. https://doi.org/10.1016/0001-8791(80)90056-1.

Tan, C. L., \& Kramer, M. W. (2012). Communication and voluntary downward career changes. Journal of Applied Communication Research, 40(1), 87-106. http://doi.org/10.1080/0 0909882.2011 .634429 .

Teixeira, M. A. P., Castro, G. D., \& Piccolo, L. R. (2007). Adaptação à universidade em estudantes universitários: Um estudo correlacional. Interação em Psicologia, 11(2), 211220. http://doi.org/10.5380/psi.v11i2.7466.

Teixeira, M. A. P., \& Gomes, W. B. (2004). Estou me formando... e agora? Reflexões e perspectivas de jovens formandos universitários. Revista Brasileira de Orientação Profissional, 5(1), 47-62.

Tosi, P. C. S., \& Botomé, S. P. (2003). A inserção e a atuação do psicólogo em diversos contextos sociais. Revista Psicologia: Organizações e Trabalho, 3(2), 217-222.

Travassos, R., \& Mourão, L. (2018). Lacunas de competências de egressos do curso Psicologia na visão dos docentes. Psicologia: Ciência e Profissão, 38(2), 233-248. https://doi. org/10.1590/1982-3703004472016.

Uvaldo, M. C. C. (2010). Tecendo a trama identitária: Um estudo sobre mudanças de carreira [Tese de Doutorado, Universidade de São Paulo]. Biblioteca Digital de Teses e Dissertações da USP. https://teses.usp.br/teses/disponiveis/47/47134/tde-06052010-120910/pt-br.php.

Veloso, E. F. R., \& Dutra, J. S. (2011). Carreiras sem Fronteiras na gestão pessoal da transição profissional: Um estudo com ex-funcionários de uma instituição privatizada. Revista de Administração Contemporânea, 15(5), 834-854. https://doi.org/10.1590/S1415-65552011000500004.

Yamamoto, O. H., Souza, J. A. J., Silva, N., \& Zanelli, J. C. (2010). A formação básica, pós-graduada e complementar do psicólogo no Brasil. In A.V.B. Bastos, \& S. M. G. Gondim (Orgs.). O trabalho do psicólogo no Brasil: Um exame à luz das categorias da Psicologia organizacional e do trabalho. Artmed.

Data de submissão: 12/12/2019 Data da primeira decisão editorial: 01/06/2020 Aprovado em: 19/08/2020 